\title{
ENGEVISTA
}

Página da revista: http://www.uff.br/engevista/seer/

\section{Efeito de compostos inibidores na bioconversão de glicose em etanol por levedura Saccharomyces cerevisiae}

\author{
Bruna Lyra Colombi ${ }^{1}$ \\ Marilha Almeida Ortiz ${ }^{2}$ \\ Patrícia Raquel Silva Zanoni ${ }^{3}$ \\ Washington Luiz Esteves Magalhães ${ }^{4}$ \\ Lorena Benathar Ballod Tavares ${ }^{5}$
}

\begin{abstract}
Resumo: Biomassas lignocelulósicas, como resíduos agrícolas e florestais, podem servir de matriz carbônica para a fermentação e obtenção do etanol de segunda geração (2G). Porém, os açúcares fermentescíveis não estão prontamente disponíveis, precisando ser liberados por operações adicionais de pré-tratamento e hidrólise. Paralelamente, substâncias químicas com potencial efeito inibitório ao metabolismo microbiano também são formadas e podem comprometer a produtividade e o rendimento global do processo. Esse estudo teve como objetivo avaliar a influência de vanilina, ácido acético, ácido vanílico e ácido 4-hidroxibenzoico na fermentação de glicose pela levedura Saccharomyces cerevisiae JP1. O cultivo ocorreu em meio sintético composto por nutrientes e 40 g.L. $\mathrm{L}^{-1}$ de glicose, inibidor em diferentes concentrações e 3\% (v/v) de inóculo obtido em meio YPD líquido. O experimento foi conduzido a $30{ }^{\circ} \mathrm{C}$ e $150 \mathrm{rpm}$ por $22 \mathrm{~h}$. Amostras foram coletadas periodicamente para monitoramento da multiplicação celular e consumo de substrato, bem como quantificação de etanol no final do procedimento. Os resultados indicaram que vanilina $\left(0,1 ; 0,5 ; 1,0\right.$ e 1,5 g.L - $\left.^{-1}\right)$ e ácido vanílico $\left(0,1 ; 0,5\right.$ e 1,0 g. $\left.\mathrm{L}^{-1}\right)$ inibiram o crescimento da levedura em uma extensão diretamente proporcional à concentração inicial destes no meio fermentativo. O ácido 4-hidroxibenzoico apresentou, em média, 25\% de toxicidade em relação ao crescimento celular, independente das quantidades estudadas $\left(0,1 ; 0,5\right.$ e 1,0 g.L. $\left.\mathrm{L}^{-1}\right)$.
\end{abstract}

\footnotetext{
${ }^{1}$ FURB - Universidade Regional de Blumenau

${ }^{2}$ FURB - Universidade Regional de Blumenau

${ }^{3}$ Embrapa Florestas

${ }^{4}$ Embrapa Florestas

${ }^{5}$ FURB - Universidade Regional de Blumenau
} 
ISSN: $1415-7314$

ISSN online: $2317-6717$

Total inibição do crescimento celular, consumo de glicose e produção de etanol foram observadas no meio com ácido acético em concentrações iguais ou superiores a 3,5 g.L $\mathrm{L}^{-1}$.

Palavras-chave: Etanol lignocelulósico, pré-tratamento, fermentação alcoólica, inibição.

\begin{abstract}
Lignocellulosic materials, such as agricultural and forest wastes, are potential feedstocks for the production of second generation ethanol (2G). However, fermentable sugars are not readily available, thus requiring previous pre-treatment and hydrolysis processes. Additionally, some chemicals formed during the pretreatment step can inhibit microbial metabolism and compromise the productivity and the global yield of the fermentation process. This study aimed to evaluate the influence of vanillin, acetic acid, vanillic acid and 4hydroxybenzoic acid on the fermentation of glucose by the yeast Saccharomyces cerevisiae JP1. Cultivation was carried out in a synthetic medium comprising nutrients and 40 g.L $\mathrm{L}^{-1}$ glucose, inhibitors at different concentrations and 3\% (v/v) inoculum obtained in YPD medium. The experiment was accomplished at $30{ }^{\circ} \mathrm{C}$ and $150 \mathrm{rpm}$ for $22 \mathrm{~h}$. Samples were taken periodically to monitor cell multiplication and substrate consumption, as well as determination of ethanol concentration at the end of the procedure. Vanillin $(0.1,0.5$, 1.0 and 1.5 g. $\left.\mathrm{L}^{-1}\right)$ and vanillic acid $\left(0.1,0.5\right.$ and 1.0 g. $\left.\mathrm{L}^{-1}\right)$ inhibited yeast growth in a proportional extension to their initial concentrations in the fermentation medium. 4-hydroxybenzoic acid showed an average toxicity of $25 \%$ on cell growth, regardless of the concentrations studied $\left(0.1,0.5\right.$ and 1.0 g.L $\left.\mathrm{L}^{-1}\right)$. Total inhibition of cell growth, glucose consumption and ethanol production was observed in medium with acetic acid in concentrations greater than or equal to $3.5 \mathrm{~g} . \mathrm{L}^{-1}$.
\end{abstract}

Keywords: Lignocellulosic ethanol, pretreatment, alcoholic fermentation, inhibition. 


\section{Introdução}

Com a crescente necessidade de redução da emissão de gases poluentes na atmosfera, o consumo de biocombustíveis passa a ser um importante passo para a mitigação do aquecimento global (Andrade et al. 2009). O etanol de segunda geração (2G), a partir do aproveitamento de matérias-primas lignocelulósicas, é uma opção para reduzir os problemas ambientais associados aos combustíveis fósseis e garantir a segurança energética frente à escassez e dependência do petróleo. Em geral, a parede celular dos vegetais é formada por $40-50 \%$ de celulose, $20-30 \%$ de hemicelulose e 20-30\% de lignina (Boaretto e Mazzafera 2013), dependendo da espécie (Carvalho et al. 2009).

Os processos clássicos para produção de etanol de primeira geração envolvem a fermentação direta dos açúcares por ação de microrganismos, sendo a levedura Saccharomyces cerevisiae a mais usada, estudada e que possui o metabolismo mais conhecido para esta finalidade (Borzani et al. 2001). A diferença é que no bioprocesso de etanol $2 \mathrm{G}$, primeiramente, a lignina deverá ser quebrada e a hemicelulose e a celulose hidrolisadas em pentoses e hexoses (Radomski et al. 2012).

A primeira etapa para a conversão de materiais lignocelulósicos em etanol é o prétratamento. Seu objetivo é alterar, fisicamente e/ou quimicamente, a estrutura lignocelulósica, sobretudo pela remoção de lignina, para melhorar a taxa de hidrólise por enzimas e aumentar a produção de açúcares fermentescíveis (Mosier et al. 2005). Em contrapartida, alguns compostos são formados ou liberados durante o pré-tratamento e inibem as etapas subsequentes de hidrólise enzimática e fermentação microbiana (Jönsson et al. 2013; Ko et al. 2015; Rasmussen et al. 2014), limitando a utilização eficiente do hidrolisado para produção de etanol (Palmqvist e Hahn-Hägerdal 2000).

Os compostos inibidores podem ser divididos em três grupos principais: (a) ácidos fracos, com predominância dos ácidos acético, fórmico e levulínico; (b) derivados furanos, como 5hidroximetilfurfural (HMF) e furfural; e (c) compostos fenólicos (Almeida et al. 2007; Jönsson et al. 2013; Palmqvist e Hahn-Hägerdal 2000). O ácido acético é originado dos grupos acetila presentes na hemicelulose; furfural e HMF são formados a partir de pentoses e hexoses, respectivamente; ácidos fórmico e levulínico são produtos da degradação desses furanos (Martín et al. 2007). A lignina é a principal fonte de compostos fenólicos (Jönsson et al. 2013), que também têm sido relacionados com a degradação de carboidratos (Almeida et al. 2007; Palmqvist e HahnHägerdal 2000), particularmente, glicose, xilose e arabinose (Rasmussen et al. 2014).

Os inibidores, produzidos em adição aos açúcares fermentescíveis, diminuem consideravelmente o rendimento e a produtividade de etanol, por comprometerem o desempenho dos microrganismos, ocasionando queda nas taxas de absorção de carboidratos e formação de produto (Almeida et al. 2007). Jönsson et al. (1998) apontaram os compostos fenólicos derivados 
da lignina como inibidores mais potentes que os produtos de degradação dos polissacarídeos e extrativos da madeira.

A formação e concentração de compostos inibidores variam em função da matéria-prima e da severidade do pré-tratamento empregadas no bioprocesso (Du et al. 2010; Jönsson et al. 2013; Ko et al. 2015; Klinke et al. 2004). Temperatura, tempo, pressão e pH do pré-tratamento influenciam na geração desses compostos (Klinke et al. 2004; Palmqvist e Hahn-Hägerdal 2000). Du et al. (2010) identificaram e quantificaram 40 possíveis sustâncias tóxicas geradas pela decomposição de lignocelulose, após realização de oito técnicas químicas de pré-tratamento em três matérias-primas diferentes.

A inibição microbiana é, por certo, um fator limitante na conversão em larga escala de biomassas lignocelulósicas em etanol (Klinke et al. 2004) e a compreensão da tolerância dos diferentes tipos de microrganismos aos inibidores, presentes nos hidrolisados, é de grande importância para que se realize um processo fermentativo eficiente e para a expansão das biorrefinarias. Nesse contexto, o presente estudo teve como objetivo avaliar os efeitos individuais de ácido acético e de três compostos fenólicos (ácido vanílico, vanilina e ácido 4-hidroxibenzoico) sobre o metabolismo celular e a síntese de etanol pela levedura S. cerevisiae JP1 em meio sintético de fermentação.

\section{Material e métodos}

\subsection{Microrganismo e inóculo}

Foi estudada a linhagem comercial de levedura $S$. cerevisiae JP1, adquirida da empresa AEB Bioquímica Latino Americana S/A na forma seca. Culturas ativas para inoculação foram obtidas em frascos Erlenmeyer de $250 \mathrm{~mL}$, suspendendo 0,1 g da levedura em $100 \mathrm{~mL}$ de meio de crescimento YPD líquido, constituído de $\left(\mathrm{g} . \mathrm{L}^{-1}\right)$ : glicose anidra $(20,0)$, extrato de levedura $(10,0)$ e peptona bacteriológica $(20,0)$. Previamente à inoculação, o pH do meio foi ajustado para 4,9 e este foi esterilizado em autoclave a $121{ }^{\circ} \mathrm{C}$ por $20 \mathrm{~min}$. Sob condições estéreis, incubou-se o conjunto em agitador rotativo a $150 \mathrm{rpm}$ e $30{ }^{\circ} \mathrm{C}$, durante $15 \mathrm{~h}$.

\subsection{Compostos inibidores}

Foram selecionados os seguintes compostos e concentrações $\left(\mathrm{g} . \mathrm{L}^{-1}\right)$ : ácido 4hidroxibenzoico $(0,1 ; 0,5$ e 1,0), ácido vanílico $(0,1 ; 0,5$ e 1,0$)$, vanilina $(0,1 ; 0,5 ; 1,0$ e 1,5$)$ e ácido acético $(0,5 ; 3,5$ e 6,5), para avaliar as concentrações a partir das quais observam-se impactos negativos no desempenho da fermentação. Estes foram dissolvidos em água destilada, depositados em câmara de fluxo laminar 24 horas antes do início do processo e filtrados através de membrana filtrante de nylon com $0,45 \mu \mathrm{m}$ de porosidade (Millipore). 


\subsection{Fermentação}

A fermentação ocorreu em meio sintético composto por $\left(\mathrm{g} . \mathrm{L}^{-1}\right)$ : glicose anidra $(40,0)$, extrato de levedura (0,5), $\mathrm{NaH}_{2} \mathrm{PO}_{4} \cdot \mathrm{H}_{2} \mathrm{O}(1,0), \mathrm{MgSO}_{4} \cdot 7 \mathrm{H}_{2} \mathrm{O}(0,25)$ e $\left(\mathrm{NH}_{4}\right)_{2} \mathrm{SO}_{4}(4,5), \mathrm{pH}$ ajustado para 4,9 e esterilizado em autoclave a $121{ }^{\circ} \mathrm{C}$ por $20 \mathrm{~min}$. O experimento foi conduzido em frascos Erlenmeyer de $250 \mathrm{~mL}$ com volume final de $100 \mathrm{~mL}$ de meio de fermentação adicionado do composto inibidor. Os frascos foram inoculados com $3 \%$ (v/v) de inóculo e cultivados em agitador rotativo por $22 \mathrm{~h}, 30{ }^{\circ} \mathrm{C}$ e $150 \mathrm{rpm}$.

Amostras de $4 \mathrm{~mL}$ foram coletadas periodicamente para monitoramento do crescimento celular e do consumo de glicose. A concentração de etanol foi medida no final do procedimento e a variação do $\mathrm{pH}$ no início. Todos os ensaios foram realizados em triplicata, incluindo um teste controle sob as mesmas condições experimentais, mas sem adição do composto inibidor.

\subsection{Determinações analíticas}

A concentração de glicose foi determinada por técnica enzimática-colorimétrica, empregando-se kit comercial Glicose Bioliquid (Laborclin) e espectrofotômetro com feixe de luz ajustado para $505 \mathrm{~nm}$.

A concentração celular foi estimada pela medida da turbidez, através da leitura da densidade ótica das amostras em espectrofotômetro com comprimento de onda de $600 \mathrm{nn}$. Utilizouse curva de calibração para correlação com a massa seca da levedura.

O etanol foi analisado por cromatografia líquida de alta eficiência (CLAE - FID) no Laboratório Bio4 Soluções Biotecnológicas em Curitiba, Paraná. Foi utilizado um cromatógrafo da marca Shimadzu, equipado com coluna Supercogel Ca 300 x 7,8 mm, operando em $80{ }^{\circ} \mathrm{C}$ e com água ultrapura como fase móvel $\left(0,3 \mathrm{~mL} \cdot \mathrm{min}^{-1}\right.$ nos primeiros treze minutos e depois $\left.0,5 \mathrm{~mL} \cdot \mathrm{min}^{-1}\right)$. O tempo de corrida foi de 33 minutos e o volume de injeção de $5 \mu \mathrm{L}$.

\subsection{Cálculo dos parâmetros fermentativos}

$\mathrm{O}$ fator de conversão de substrato em produto $\left(\mathrm{Y}_{\mathrm{P} / \mathrm{S}}, \mathrm{g} \cdot \mathrm{g}^{-1}\right)$ foi calculado pela razão mássica entre o etanol formado e o açúcar consumido. $\mathrm{O}$ fator de conversão de substrato em células $\left(\mathrm{Y}_{\mathrm{X} / \mathrm{S}}\right.$, $\left.\mathrm{g} \cdot \mathrm{g}^{-1}\right)$ pela razão mássica entre as células formadas e o açúcar consumido. A produtividade média de células $\left(\mathrm{P}_{\mathrm{X}}, \mathrm{g} \cdot \mathrm{L}^{-1} \cdot \mathrm{h}^{-1}\right)$ e o consumo médio de substrato $\left(\mathrm{P}_{\mathrm{S}}, \mathrm{g} \cdot \mathrm{L}^{-1} \cdot \mathrm{h}^{-1}\right)$ foram calculados, respectivamente, pela concentração de células formadas e pela concentração de açúcar consumido durante as 22 horas de fermentação. $O$ grau de inibição celular $\left(G_{X}, \%\right)$ foi estimado pela razão entre o crescimento das leveduras no meio com inibidores e o crescimento das leveduras no meio controle. $\mathrm{O}$ rendimento do processo fermentativo $(\eta, \%)$ foi determinado utilizando-se $Y_{P / S}$ e o rendimento teórico estequiométrico $(0,511)$ da conversão de glicose em etanol, segundo a Equação (1). 


$$
\eta=\left(Y_{P / S} \div 0,511\right) \times 100
$$

\section{Resultados e discussão}

Todos os compostos testados, quando presentes no meio de cultivo, reduziram o $\mathrm{pH}$ do meio em comparação com o controle (Tabela 1). Quanto maior a concentração, maior foi a alteração do $\mathrm{pH}$, exceto para vanilina e ácido acético, em que o $\mathrm{pH}$ se manteve praticamente constante após o primeiro decréscimo, independente da concentração. $\mathrm{O}$ pH do meio com ácido acético foi o que sofreu maior variação, passando de 4,9 para 3,4.

Tabela 1: Alteração dos valores de $\mathrm{pH}$ do meio de cultivo pela presença dos compostos estudados

\begin{tabular}{ccc}
\hline Compostos & pH inicial & Variação do $\mathrm{pH}^{*}(\%)$ \\
Controle & 4,9 & - \\
Vanilina 0,1 g/L & 4,4 & 10,2 \\
Vanilina 0,5 g/L & 4,4 & 10,2 \\
Vanilina 1,0 g/L & 4,4 & 10,2 \\
Vanilina 1,5 g/L & 4,5 & 8,2 \\
Ácido acético 0,5 g/L & 3,5 & 28,6 \\
Ácido acético 3,5 g/L & 3,5 & 28,6 \\
Ácido acético 6,5 g/L & 3,4 & 30,6 \\
Ácido vanílico 0,1 g/L & 4,1 & 16,3 \\
Ácido vanílico 0,5 g/L & 3,7 & 24,5 \\
Ácido vanílico 1,0 g/L & 3,5 & 28,6 \\
Ácido 4-hidroxibenzoico 0,1 g/L & 4,4 & 10,2 \\
Ácido 4-hidroxibenzoico 0,5 g/L & 3,9 & 20,4 \\
Ácido 4-hidroxibenzoico 1,0 g/L & 3,7 & 24,5 \\
\hline
\end{tabular}

*Variação do pH do meio de cultivo em relação ao meio controle

Oliva et al. (2003) estudaram o efeito do pH inicial na toxicidade de ácidos orgânicos a uma concentração de 5 g.L $\mathrm{L}^{-1}$ na fermentação alcoólica de glicose por Kluyveromyces marxianus. O efeito tóxico de todos os ácidos testados (inclusive o ácido acético, ácido 4-hidroxibenzoico e ácido vanílico) foi potencializado com a redução do $\mathrm{pH}$ de 5,5 para 4,0. Comportamento similar foi 
identificado por Bellissimi et al. (2009), quando analisaram os efeitos do ácido acético (3 g.L $\left.\mathrm{L}^{-1}\right)$ sobre a cinética de fermentação de $S$. cerevisiae em pH 5,0 e pH 3,5.

Quando o pH do meio é baixo, o ácido acético $(\mathrm{pKa}=4,75)$ aparece na forma não dissociada, é lipossolúvel e capaz de penetrar a parede celular dos microrganismos por difusão. Uma vez no interior da célula, dissocia-se devido ao $\mathrm{pH}$ neutro encontrado, descarregando prótons e acidificando o citoplasma, desestabilizando o equilíbrio fisiológico, inibindo e causando morte celular. Seu efeito inibitório pode ser atenuado com fermentações em $\mathrm{pH}$ controlado, acima do valor de pKa (Lawford e Rousseau 1998). Pereira et al. (2011) observaram que em meios não tamponados, o ácido acético influenciou negativamente o fator de conversão de xilose em xilitol e a produtividade volumétrica em xilitol por Candida guilliermondii, como uma consequência da diminuição do pH. Ao passo que o tamponamento do meio favoreceu os parâmetros fermentativos, aumentando a concentração de xilitol de 15,5 para 46,2 g.L $\mathrm{L}^{-1}$.

O consumo de glicose e o crescimento da levedura $S$. cerevisiae JP1 são apresentados nas Figuras 1 a 4 .

Verifica-se que o consumo de glicose foi drasticamente afetado nos meios contendo vanilina 1,5 g. $\mathrm{L}^{-1}$ e ácido acético 3,5 g. $\mathrm{L}^{-1}$ e 6,5 g. $\mathrm{L}^{-1}$. Para os demais compostos, o consumo de glicose foi análogo, gerando um resíduo de aproximadamente 20 g.L $\mathrm{L}^{-1}$. Para o crescimento celular, os mesmos compostos que influenciaram no consumo de glicose, limitaram a multiplicação de JP1. Os resultados dos parâmetros fermentativos são mostrados na Tabela 2.

Destaque deve ser dado para o ácido acético, que inibiu totalmente o crescimento celular a partir de 3,5 g.L $\mathrm{L}^{-1}$. Pereira et al. (2011) avaliaram o efeito do ácido acético $\left(0,8\right.$ a 2,6 g.L $\left.\mathrm{L}^{-1}\right)$ para produção de xilitol por $C$. guilliermondii e constataram que na concentração de 2,6 g.L ${ }^{-1}$ o ácido se torna tóxico para a célula, reduzindo o seu crescimento e afetando negativamente o consumo de xilose. Lee et al. (2011), estudando a tolerância de S. cerevisiae K35 aos compostos inibidores, também verificaram uma limitação do crescimento mais acentuada nas concentrações de ácido acético superiores a 4 g.L . $^{-1}$.
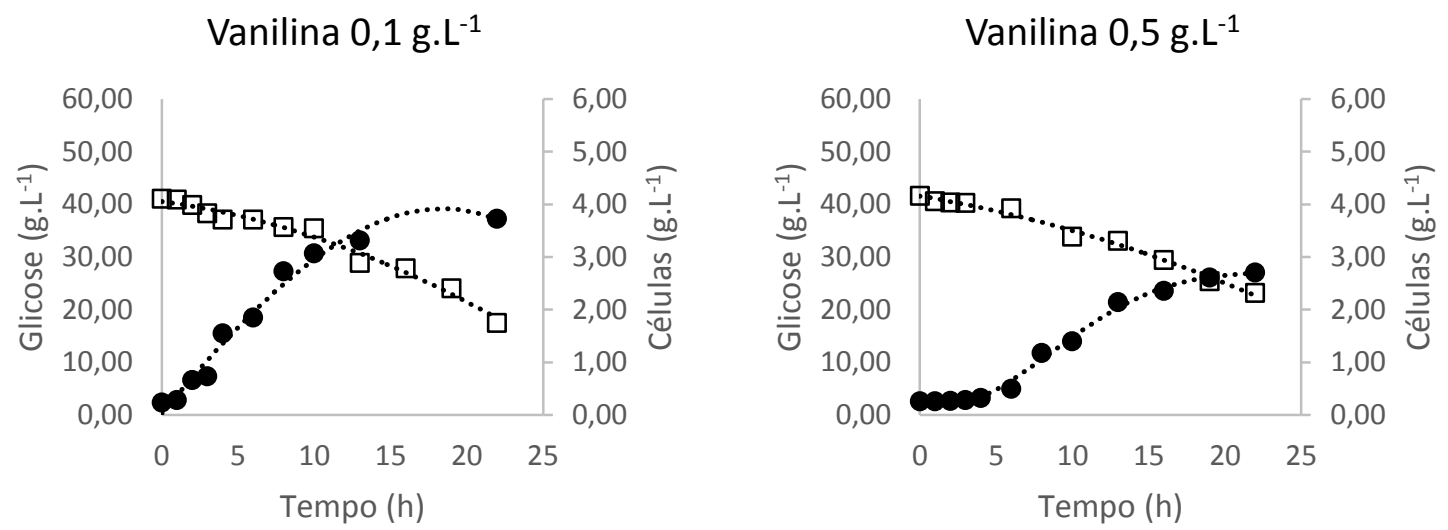
ISSN: $1415-7314$

ISSN online: $2317-6717$

Vanilina $1,0 \mathrm{~g} \cdot \mathrm{L}^{-1}$

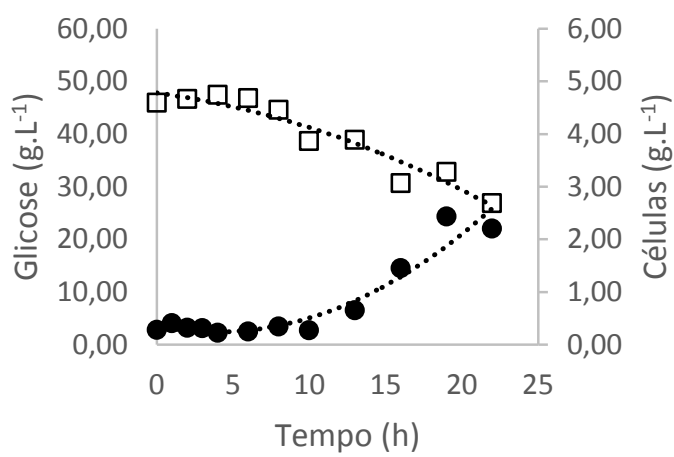

Vanilina $1,5 \mathrm{~g} \cdot \mathrm{L}^{-1}$

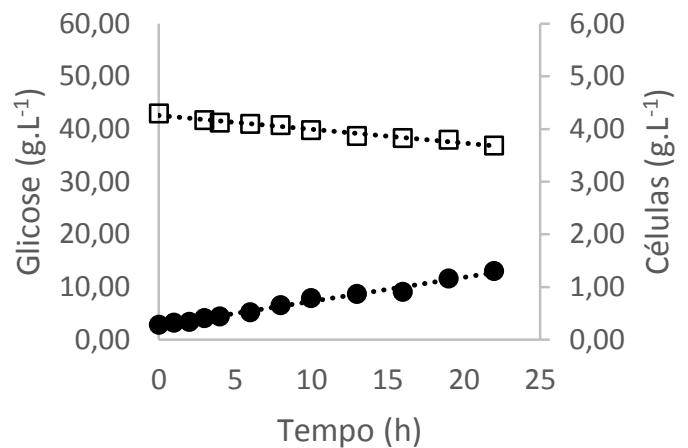

Figura 1: Perfil cinético de crescimento celular $(\bullet)$ e consumo de glicose $(\square)$ por Saccharomyces cerevisiae JP1 em meio sintético com diferentes concentrações de vanilina

Ácido Acético 0,5 g.L.-1

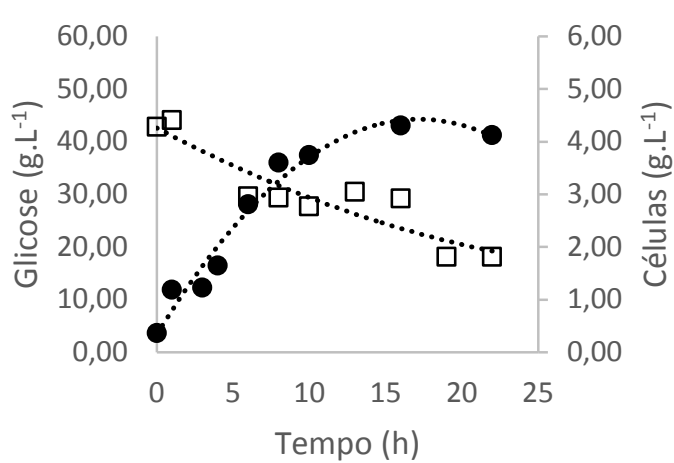

Ácido Acético 3,5 g.L-1

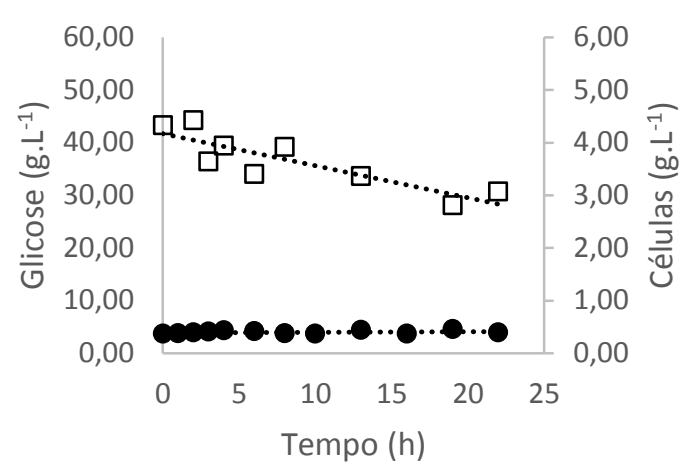

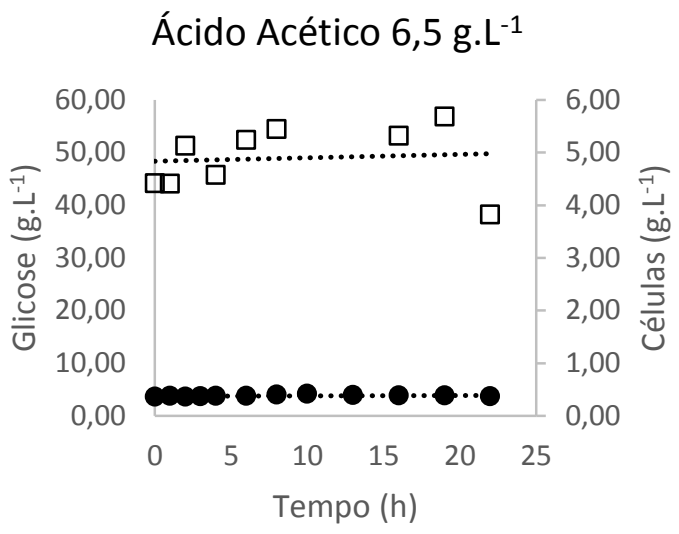

Figura 2: Perfil cinético de crescimento celular $(\bullet)$ e consumo de glicose $(\square)$ por Saccharomyces cerevisiae JP1 em meio sintético com diferentes concentrações de ácido acético 
ISSN: $1415-7314$

ISSN online: $2317-6717$

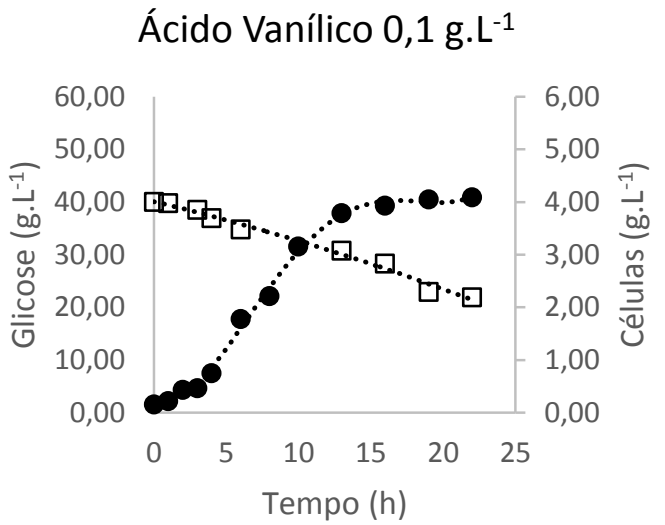

Ácido Vanílico 0,5 g.L $\mathrm{L}^{-1}$

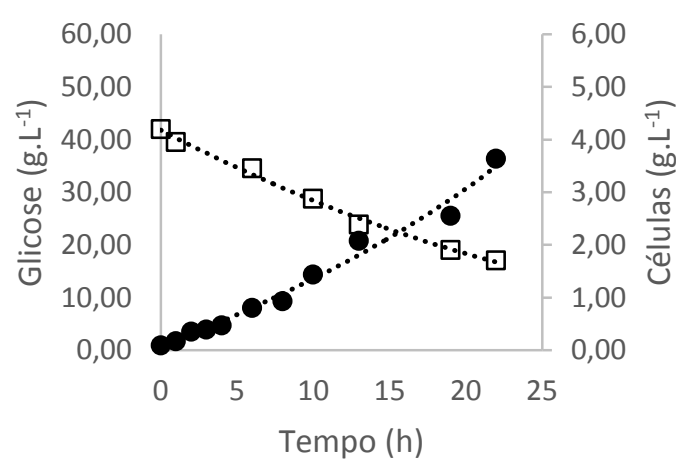

Ácido Vanílico 1,0 g.L $\mathrm{L}^{-1}$

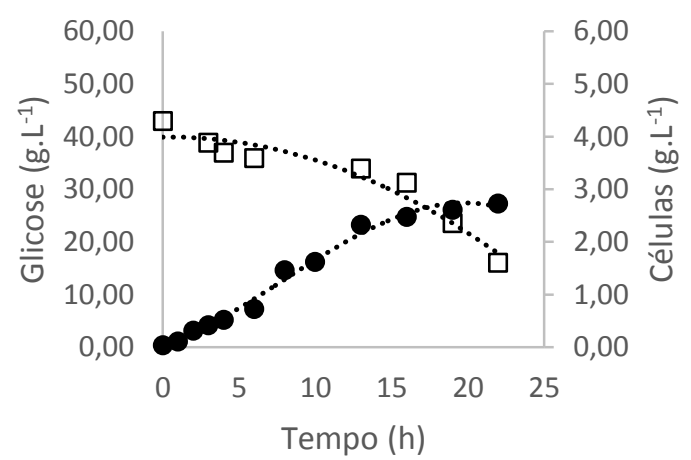

Figura 3: Perfil cinético de crescimento celular $(\bullet)$ e consumo de glicose ( $\square$ ) por Saccharomyces cerevisiae JP1 em meio sintético com diferentes concentrações de ácido vanílico

Ácido 4-Hidroxibenzoico 0,1 g.L-1

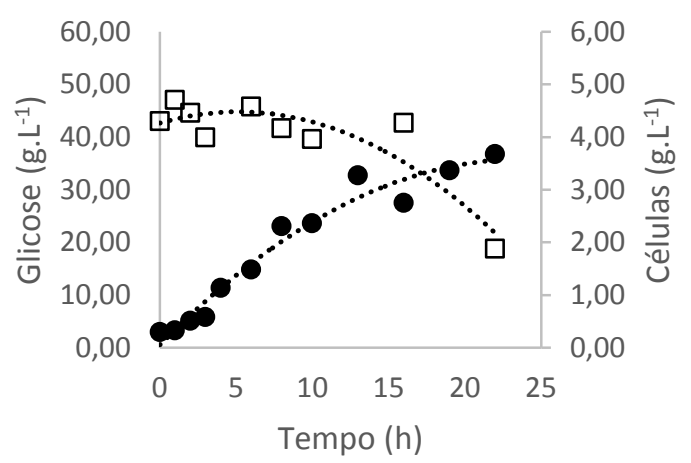

Ácido 4-Hidroxibenzoico 0,5 g.L-1

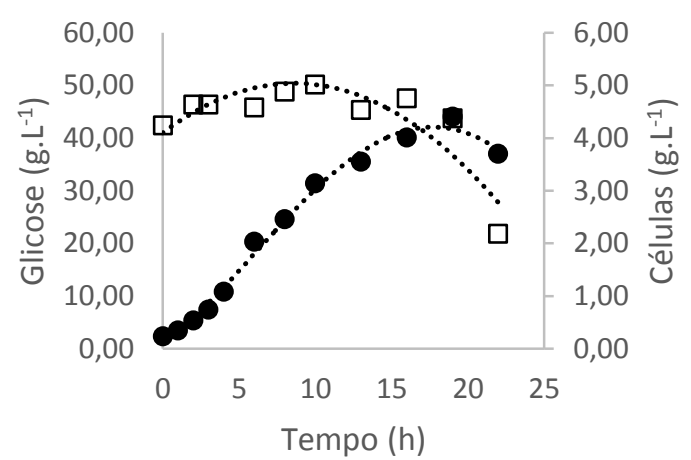




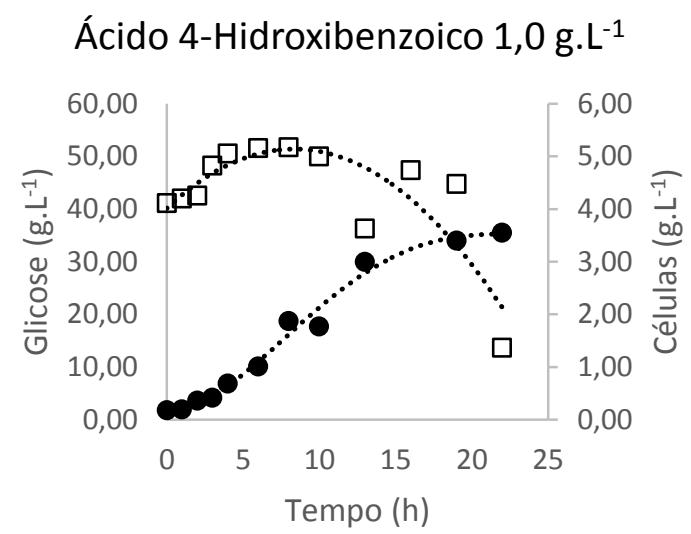

Figura 4: Perfil cinético de crescimento celular $(\bullet)$ e consumo de glicose $(\square)$ por Saccharomyces cerevisiae JP1 em meio sintético com diferentes concentrações de ácido 4-hidroxibenzoico

Tabela 2: Efeito de diferentes concentrações dos compostos nos parâmetros de crescimento e consumo de substrato de Saccharomyces cerevisiae JP1 em meio sintético

\begin{tabular}{|c|c|c|c|c|}
\hline Compostos & $\begin{array}{c}\mathrm{Y}_{\mathrm{X} / \mathrm{S}} \\
\left(\mathrm{g} \cdot \mathrm{g}^{-1}\right)\end{array}$ & $\begin{array}{c}\mathrm{P}_{\mathrm{X}} \\
\left(\mathrm{g} \cdot \mathrm{L}^{-1} \cdot \mathrm{h}^{-1}\right)\end{array}$ & $\begin{array}{c}\mathrm{P}_{\mathrm{S}} \\
\left(\mathrm{g} \cdot \mathrm{L}^{-1} \cdot \mathrm{h}^{-1}\right)\end{array}$ & $\begin{array}{l}\mathrm{G}_{\mathrm{X}} \\
(\%)\end{array}$ \\
\hline Controle & 0,19 & 0,21 & 1,09 & - \\
\hline Vanilina $0,1 \mathrm{~g} \cdot \mathrm{L}^{-1}$ & 0,15 & 0,16 & 1,07 & 24 \\
\hline Vanilina $0,5 \mathrm{~g} \cdot \mathrm{L}^{-1}$ & 0,13 & 0,11 & 0,84 & 46 \\
\hline Vanilina $1,0 \mathrm{~g} \cdot \mathrm{L}^{-1}$ & 0,10 & 0,09 & 0,87 & 58 \\
\hline Vanilina $1,5 \mathrm{~g} \cdot \mathrm{L}^{-1}$ & 0,17 & 0,05 & 0,28 & 78 \\
\hline Ácido acético 0,5 g.L $\mathrm{L}^{-1}$ & 0,15 & 0,17 & 1,12 & 18 \\
\hline Ácido acético 3,5 g.L $\mathrm{L}^{-1}$ & 0,00 & 0,00 & 0,57 & 99 \\
\hline Ácido acético 6,5 g.L $\mathrm{L}^{-1}$ & 0,00 & 0,00 & 0,27 & 100 \\
\hline Ácido vanílico 0,1 g.L $\mathrm{L}^{-1}$ & 0,22 & 0,18 & 0,83 & 14 \\
\hline Ácido vanílico 0,5 g.L $\mathrm{L}^{-1}$ & 0,14 & 0,16 & 1,13 & 22 \\
\hline Ácido vanílico 1,0 g.L $\mathrm{L}^{-1}$ & 0,10 & 0,12 & 1,22 & 41 \\
\hline Ácido 4-hidroxibenzoico 0,1 g... $\mathrm{L}^{-1}$ & 0,14 & 0,15 & 1,10 & 26 \\
\hline Ácido 4-hidroxibenzoico $0,5 \mathrm{~g} . \mathrm{L}^{-1}$ & 0,17 & 0,16 & 0,93 & 24 \\
\hline Ácido 4-hidroxibenzoico 1,0 g.L $\mathrm{L}^{-1}$ & 0,12 & 0,15 & 1,25 & 26 \\
\hline
\end{tabular}

Segundo Rossell (2006), muitos compostos fenólicos presentes nos hidrolisados lignocelulósicos são prejudiciais ao metabolismo de diversas leveduras fermentativas, incluindo o ácido 4-hidroxibenzoico, o ácido vanílico e a vanilina. Fato este percebido pelos valores da Tabela 2. Esses inibidores causam perda de integridade da membrana biológica, afetando sua capacidade 
de servir como barreira seletiva, o crescimento celular e a assimilação de açúcar (Almeida et al. 2007; Chandel et al. 2013; Palmqvist e Hahn-Hägerdal 2000).

Os resultados obtidos mostraram que o crescimento da levedura S. cerevisiae JP1 foi inversamente proporcional à concentração de vanilina no meio de cultivo, que prolongou a fase lag e diminuiu a produtividade média de células ( $\mathrm{Px}$ ) e o consumo médio de substrato (Ps). O grau de inibição apresentou um perfil praticamente linear com a concentração, partindo de $24 \%$ em 0,1 g.L' ${ }^{1}$ e atingindo $78 \%$ em 1,5 g.L $\mathrm{L}^{-1}$. Comportamento similar já havia sido apontado por Delgenes et al. (1996) e por Larsson et al. (2000), quando 1 g.L $\mathrm{L}^{-1}$ de vanilina foi acrescentada ao meio de cultura e apresentou forte inibição às leveduras fermentativas de xilose e $S$. cerevisiae.

Para o ácido vanílico, efeitos mais significativos surgiram com o aumento da sua concentração de 0,1 para 1,0 g.L. $\mathrm{L}^{-1}$ no meio. Uma menor produtividade de biomassa (Px) pode ser observada, com aumento do grau de inibição, entre 14 e 41\%, em relação ao controle. O consumo médio de substrato (Ps) elevou-se, porém, o fator de conversão de substrato em células ( $\mathrm{Yx} / \mathrm{s})$ decaiu. O mesmo ocorreu nos estudos de Furlani (2014), onde o ácido vanílico (0,6 e 1,0 g.L ${ }^{-1}$ ) dificultou a fermentação alcoólica pela levedura $S$. cerevisiae de panificação, diminuindo o consumo de glicose e o Yx/s, bem como a produção e a produtividade volumétrica de etanol. No entanto, o crescimento de Fusarium oxysporum em meio com glicose não sofreu nenhuma inibição quando 1,25 e 6,25 g.L $\mathrm{L}^{-1}$ de ácido vanílico foram adicionados (Xiros et al. 2011). Diferentes resultados são, provavelmente, devido ao tipo de microrganismo e condições experimentais utilizadas.

No geral, o ácido 4-hidroxibenzoico foi o único composto que apresentou grau de inibição constante em todas as quantidades testadas, com uma média de 25\%. Zhang et al. (2014), avaliando o efeito de quatro compostos aromáticos (aldeído coniferílico, vanilina, ácido ferúlico e ácido 4hidroxibenzoico) sobre o crescimento de Gluconacetobacter xylinus, encontraram o ácido 4hidroxibenzoico como o inibidor menos potente. Na gama de concentrações testadas pelos autores, de 0,5 a $10 \mathrm{mM}\left(0,069\right.$ a 1,38 g. $\left.\mathrm{L}^{-1}\right)$, este não manifestou qualquer efeito nitidamente negativo sobre o consumo de glicose e viabilidade celular. A adição deste ácido nas concentrações entre 0,1 e 1,0 g.L $\mathrm{L}^{-1}$, por exemplo, também não ocasionou alterações significativas nos parâmetros fermentativos avaliados por Furlani (2014), durante fermentação alcoólica pela levedura $S$. cerevisiae. Segundo Oliva et al. (2003), a concentração de ácido 4-hidroxibenzoico necessária para inibir 50\% do crescimento de K. marxianus, em 24 horas, é de 3,10 g.L $\mathrm{L}^{-1}$.

Quanto ao efeito dos compostos sobre a bioconversão de glicose em etanol, constatou-se que o aumento da concentração afetou negativamente o bioprocesso (Tabela 3). Conforme Martín et al. (2007), vários compostos gerados no pré-tratamento atuam sobre o metabolismo de $S$. cerevisiae, comprometendo a rota de produção alcoólica.

Como esperado, a produção de etanol no ensaio controle foi superior aos demais experimentos que continham os compostos testados. A completa ausência de etanol foi observada 
apenas no meio com ácido acético em concentração igual ou acima de $3,5 \mathrm{~g} . \mathrm{L}^{-1}$, onde não houve crescimento da levedura JP1. Xiros et al. (2011) apontaram, pelos seus experimentos com compostos individuais, que o ácido acético pode ser o principal inibidor durante os processos de conversão de materiais lignocelulósicos em biocombustíveis líquidos. O teste contendo 0,5 g.L $\mathrm{L}^{-1}$ do composto 4-hidroxibenzoico obteve o melhor rendimento, apresentando $89 \%$ do valor de controle.

Tabela 3: Efeito de diferentes concentrações dos compostos sobre a bioconversão de glicose em etanol pela levedura Saccharomyces cerevisiae JP1

\begin{tabular}{cccc}
\hline Compostos & Etanol $\left(\mathrm{g} \cdot \mathrm{L}^{-1}\right)$ & $\mathrm{Y}_{\mathrm{P} / \mathrm{S}}\left(\mathrm{g} \cdot \mathrm{g}^{-1}\right)$ & $\eta(\%)$ \\
\hline Controle & 9,6 & 0,40 & 78,3 \\
Vanilina 0,1 g/L & 3,6 & 0,15 & 29,9 \\
Vanilina 0,5 g/L & 6,4 & 0,35 & 68,0 \\
Vanilina 1,0 g/L & 6,5 & 0,34 & 66,7 \\
Vanilina 1,5 g/L & 1,4 & 0,23 & 45,0 \\
Ácido acético 0,5 g/L & 5,8 & 0,24 & 46,0 \\
Ácido acético 3,5 g/L & 0,0 & 0,00 & 0,00 \\
Ácido acético 6,5 g/L & 0,0 & 0,00 & 0,00 \\
Ácido vanílico 0,1 g/L & 5,0 & 0,28 & 53,9 \\
Ácido vanílico 0,5 g/L & 7,3 & 0,29 & 57,4 \\
Ácido vanílico 1,0 g/L & 4,0 & 0,15 & 29,1 \\
Ácido 4-hidroxibenzoico 0,1 g/L & 7,0 & 0,29 & 56,5 \\
Ácido 4-hidroxibenzoico 0,5 g/L & 7,3 & 0,36 & 69,6 \\
Ácido 4-hidroxibenzoico 1,0 g/L & 3,4 & 0,12 & 24,2 \\
\hline
\end{tabular}

\section{Conclusões}

Vanilina, ácido acético, ácido vanílico e ácido 4-hidroxibenzoico, compostos potencialmente gerados no pré-tratamento de materiais lignocelulósicos, afetam o metabolismo de S. cerevisiae JP1 durante a fermentação de glicose em etanol. O efeito tóxico depende da concentração desses no meio fermentativo, exceto para o ácido 4-hidroxibenzoico, sendo necessária a remoção quando em quantidades significativas. Os resultados indicam que vanilina e ácido vanílico inibem o crescimento da levedura em uma extensão diretamente proporcional à concentração inicial dessas moléculas.

Diante disso, estudos futuros envolvendo diferentes inibidores, efeitos de sinergia e detoxificação dos hidrolisados são necessários para se desenvolver processos de bioconversão mais viáveis em grande escala. 


\section{Agradecimentos}

Os autores são gratos à Coordenação de Aperfeiçoamento de Pessoal de Nível Superior (CAPES), ao Conselho Nacional de Desenvolvimento Científico e Tecnológico (CNPq) e à Embrapa Florestas.

\section{Referências}

ALMEIDA, J. R. M., MODIG, T., PETERSSON, A., HAHN-HÄGERDAL, B., LIDÉN, G., GORWA-GRAUSLUND, M. F. 2007. Increased tolerance and conversion of inhibitors in lignocellulosic hydrolysates by Saccharomyces cerevisiae. Journal of Chemical Technology and Biotechnology, 82, 340-349.

ANDRADE, E. T., CARVALHO, S. R. G., SOUZA, L. F. 2009. Programa do Proálcool e o etanol no Brasil. Engevista, 11 (2), 127-136.

BELLISSIMI, E., DIJKEN, J. P. V., PRONK, J. T., MARIS, A. J. A. V. 2009. Effects of acetic acid on the kinetics of xylose fermentation by an engineered, xylose-isomerase-based Saccharomyces cerevisiae strain. FEMS Yeast Research, 9, 358-364.

BOARETTO, L. F., MAZZAFERA, P. 2013. The proteomes of feedstocks used for the production of second-generation ethanol: a lacuna in the biofuel era. Annals of Applied Biology, 163, 12-22.

BORZANI, W., LIMA, U. A., AQUARONE, E., SCHMIDELL, W. 2001. Biotecnologia Industrial, Edgard Blücher, São Paulo.

CARVALHO, L. C., BUENO, R. C. O. F., CARVALHO, M. M., FAVORETO, A. L., GODOY, A. F. 2013. Cana-de-açúcar e álcool combustível: histórico, sustentabilidade e segurança energética. Enciclopédia Biosfera, 9 (16), 531-543.

CHANDEL, A. K., SILVA, S. S., SINGH, O. V. 2013. Detoxification of lignocellulose hydrolysates: biochemical and metabolic engineering toward white biotechnology. Bioenergy Research, 6, 388-401.

DELGENES, J. P., MOLETTA, R., NAVARRO, J. M. 1996. Effects of lignocellulose degradation products on ethanol fermentations of glucose and xylose by Saccharomyces cerevisiae, Zymomonas mobilis, Pichia stipitis, and Candida shehatae. Enzyme and Microbial Technology, 19, 220-225.

DU, B., SHARMA, L. N., BECKER, C., CHEN, S., MOWERY, R. A., WALSUM, G. P. V., CHAMBLISS, C. K. 2010. Effect of varying feedstock-pretreatment chemistry combinations on the formation and accumulation of potentially inhibitory degradation products in biomass hydrolysates. Biotechnology and Bioengineering, 107 (3), 430-440.

FURLANI, J. M. S. 2014. Influência de compostos fenólicos na fermentação de glicose a etanol por Saccharomyces cerevisiae PE-2 e Saccharomyces cerevisiae de panificação e identificação de seus produtos de bioconversão. Tese de Doutorado, Escola de Engenharia de Lorena da Universidade de São Paulo.

JÖNSSON, L. J., PALMQVIST, E., NILVEBRANT, N., HAHN-HÄGERDAL, B. 1998. Detoxification of wood hydrolysates with laccase and peroxidase from the white-rot fungus Trametes versicolor. Applied Microbiology and Biotechnology, 49, 691-697.

JÖNSSON, L. J., ALRIKSSON, B., NILVEBRANT, N. 2013. Bioconversion of lignocellulose: inhibitors and detoxification. Biotechnology for Biofuels, 6, 1-10.

KLINKE, H. B., THOMSEN, A. B., AHRING, B. K. 2004. Inhibition of ethanol-producing yeast and bacteria by degradation products produced during pre-treatment of biomass. Applied Microbiology and Biotechnology, 66, 10-26.

KO, J. K., UM, Y., PARK, Y., SEO, J., KIM, K. H. 2015. Compounds inhibiting the bioconversion of hydrothermally pretreated lignocellulose. Applied Microbiology and Biotechnology, 99, 42014212.

LARSSON, S., QUINTANA-SÁINZ, A., REIMANN, A., NILVEBRANT, N. O., JÖNSSON, L. J. 2000. Influence of lignocellulose-derived aromatic compounds on oxygen-limited growth and ethanolic fermentation by Saccharomyces cerevisiae. Applied Biochemistry and Biotechnology, 84$86,617-632$. 
LAWFORD, H. G., ROUSSEAU, J. D. 1998. Improving fermentation performance of recombinant Zymomonas in acetic acid-containing media. Applied Biochemistry and Biotechnology, 70-72, 161172.

LEE, H., CHO, D. H., KIM, Y. H., SHIN, S., KIM, S. B., HAN, S. O., LEE, J., KIM, S.W., PARK, C. 2011. Tolerance of Saccharomyces cerevisiae K35 to lignocellulose-derived inhibitory compounds. Biotechnology and Bioprocess Engineering, 16 (4), 755-760.

MARTÍN, C., ALMAZÁN, O., MARCET, M., JÖNSSON, L. J. 2007. A study of three strategies for improving the fermentability of sugarcane bagasse hydrolysates for fuel ethanol production. International Sugar Journal, 109 (1297), 33-39.

MOSIER, N., WYMAN, C., DALE, B., ELANDER, R., LEE, Y. Y., HOLTZAPPLE, M., LADISCH, M. 2005. Features of promising technologies for pretreatment of lignocellulosic biomass. Bioresource Technology, 96 (6), 673-686.

PALMQVIST, E., HAHN-HÄGERDAL, B. 2000. Fermentation of lignocellulosic hydrolysates. II: Inhibitors and mechanisms of inhibition. Bioresource Technology, 74, 25-33.

OlivA, J. M., SÁEZ, F., BALleSTEROS, I., GONZÁlEZ, A., NEGRO, M. J., MANZANARES, P., BALLESTEROS, M. 2003. Effect of lignocellulosic degradation compounds from steam explosion pretreatment on ethanol fermentation by thermotolerant yeast Kluyveromyces marxianus. Applied Biochemistry and Biotechnology, 105-108, 141-153.

PEREIRA, R. S., MUSSATTO, S. I., ROBERTO, I. C. 2011. Inhibitory action of toxic compounds present in lignocellulosic hydrolysates on xylose to xylitol bioconversion by Candida guilliermondii. Journal of Industrial Microbiology and Biotechnology, 38, 71-78.

RADOMSKI, B. M., GONZALEZ, W. A., FIAUX, S. B. 2012. Tratamento da biomassa lignocelulósica da cadeia produtiva de dendê (Elaeis guineensis) para produção de glicose por hidrólise ácida. Revista de Química Industrial, 734, 19-25.

RASMUSSEN, H., SØRENSEN, H. R., MEYER, A. S. 2014. Formation of degradation compounds from lignocellulosic biomass in the biorefinery: sugar reaction mechanisms. Carbohydrate Research, 385, 45-57.

ROSSELL, C. E. V. 2006. Conversion of lignocellulose biomass (bagasse and straw) from the sugar-alcohol industry into bioethanol. In: FRANCO, T. T. (ed.) Industrial Perspectives for Bioethanol. São Paulo.

XIROS, C., VAFIADI, C., PASCHOS, T., CHRISTAKOPOULOS, P. 2011. Toxicity tolerance of Fusarium oxysporum towards inhibitory compounds formed during pretreatment of lignocellulosic materials. Journal of Chemical Technology and Biotechnology, 86, 223-230.

ZHANG, S., WINESTRAND, S., GUO, X., CHEN, L., HONG, F., JÖNSSON, L. J. 2014. Effects of aromatic compounds on the production of bacterial nanocellulose by Gluconacetobacter xylinus. Microbial Cell Factories, 13, 1-10. 